\title{
PENGARUH KEPEMIMPINAN DAN MOTIVASI KERJA TERHADAP DISIPLIN KERJA PEGAWAI (SEBUAH KAJIAN EKONOMI SUMBER DAYA MANUSIA STUDI KASUS PADA PT. BANK MUAMALAT INDONESIA CABANG PEMATANGSIANTAR)
}

\author{
Muhammad Fauzan \\ Sekolah Tinggi Ilmu Komputer (STIKOM) Tunas Bangsa Pematangsiantar, Indonesia \\ Jalan Jenderal Sudirman, Pematangsiantar, Sumut 21127 Indonesia, Phone +62-22-22431 \\ E-mail Korespondensi: mfauzan57@yahoo.com
}

Naskah Diterima: Januari 2017; Disetujui: April 2017

\begin{abstract}
The aim of this study is to determine the effect of leadership and motivation to employees' discipline in PT. Bank Muamalat Indonesia Pematangsiantar branch. The data collection method of the research is conducted by distributing questionnaires to 25 employees of PT. Bank Muamalat Indonesia Pematangsiantar branch. Leadership (X1) and motivation variable (X2) simultaneously have positive and significant impact on employees' discipline in PT. Bank Muamalat Indonesia Pematangsiantar branch. It can be seen from the value of $F_{\text {test }}=$ $3.287>F_{\text {tabel }}=3.101$. At the level of error $a=5 \%$, the value of the $F_{\text {test }}$ was significant, with significance $=0.411<$ error level $a=5 \%$. T-test for leadership variable (X1) is 0.676 , for employee's motivation variable (X2) is 0.875 . Based on the hypothesis of criteria if $\boldsymbol{t}_{\text {test }}<\boldsymbol{t}_{\text {tabel }}$ then $\mathrm{H}_{0}$ is accepted; and $\mathrm{H}_{1}$ is rejected. From determination identification is known that the correlation coefficient of 0.550 which showed a very strong relationship in which the coefficient of determination (adjusted $R^{2}$ ) for 0.379 is between $0 \leq R 2 \leq 1$. And it can be concluded that the variables of leadership and working motivation of employees have significant effect on employees' discipline at PT. Bank Muamalat Indonesia Pematangsiantar branch.
\end{abstract}

Keywords: leadership, work motivation, employees' discipline JEL Classification: E24, O15, J10

Abstrak: Tujuan penelitian ini adalah untuk mengetahui pengaruh kepemimpinan dan motivasi kerja terhadap disiplin pegawai di PT. Bank Muamalat Indonesia cabang Pematangsiantar. Penelitian ini dilakukan dengan metode pengumpulan data dengan cara penyebaran kuesioner pada 25 orang pegawai PT. Bank Muamalat Indonesia cabang Pematangsiantar. Variabel kepemimpinan $\left(X_{1}\right)$ dan motivasi kerja $\left(X_{2}\right)$ secara bersama-sama berpengaruh positif dan signifikan terhadap motivasi kerja pada PT. Bank Muamalat Indonesia cabang Pematangsiantar. Hal ini dapat dilihat dari nilai $F_{\text {test }}=3.287>F_{\text {tabel }}=3.101$. Pada tingkat kesalahan a $=5 \%$, nilai $F_{\text {hitung }}$ tersebut dinyatakan signifikan, dengan signifikansi $=0.411<$ tingkat kesalahan $a=5 \%$. Nilai thitung untuk variabel kepemimpinan $\left(X_{1}\right)$ adalah 0.676, untuk variabel motivasi kerja pegawai $\left(\mathrm{X}_{2}\right)$ adalah 0.875 . Berdasarkan kriteria uji hipotesis yaitu jika $t_{\text {hitung }}<t_{\text {tabel }}$ maka $\mathrm{H}_{0}$ diterima; da $\mathrm{H}_{1}$ ditolak. Berdasarkan uji determinasi diketahui bahwa koefisien korelasi sebesar 0.550 yang menunjukkan adanya hubungan yang sangat kuat dimana koefisien determinasi $\left(R^{2}\right)$ yang telah disesuaikan sebesar 0.379 berada di antara $0 \leq R^{2} \leq 1$. Dan dapat disimpulkan bahwa variabel kepemimpinan dan motivasi kerja pegawai berpengaruh signifikan terhadap disiplin kerja pegawai pada kantor PT. Bank Muamalat Indonesia cabang Pematangsiantar.

Kata kunci: kepemimpinan, motivasi kerja, disiplin pegawai

Klasifikasi JEL: E24, O15, J10 


\section{PENDAHULUAN}

Dalam suatu organisasi atau perusahaan, kepemimpinan menunjukkan salah satu faktor yang penting. Kepemimpinan adalah upaya mempengaruhi banyak orang melalui komunikasi untuk mencapai tujuan, cara mempengaruhi orang dengan petunjuk atau perintah, tindakan yang menyebabkan orang lain bertindak atau merespon dan menimbulkan perubahan positif, kekuatan dinamis penting yang memotivasi dan mengkoordinasikan organsisasi dalam mencapai tujuan, kemampuan untuk menciptakan rasa percaya diri dan dukungan diantara bawahan agar tujuan organisasi dapat tercapai (Brahmasari, 2008).

Kepemimpinan merupakan faktor yang penting dalam memberikan pengarahan kepada pegawai apalagi pada saat-saat sekarang ini dimana semua serba terbuka, maka kepemimpinan yang dibutuhkan adalah kepemimpinan yang bisa memberdayakan pegawainya. Kepemimpinan yang bisa menumbuhkan motivasi kerja pegawai adalah kepemimpinan yang bisa menumbuhkan rasa percaya diri kepada pegawai dalam menjalankan tugasnya masing-masing. Kepemimpinan merupakan salah satu faktor yang menunjang mtoivasi pegawai dalam bekerja. Pemimpin yang baik akan memberikan situasi yang kondusif kepada pegawai untuk menyelesaikan segala sesuatu yang diberikan kepada mereka. "Kepemimpinan adalah cara seorang pemimpin mempengaruhi perilaku bawahan, agar mau bekerjasama dan bekerja secara produktif untuk mencapai tujuan organisasi". (Malayu S.P. Hasibuan, 2002).

Salah satu tantangan yang cukup berat yang sering harus dihadapi oleh pemimpin adalah bagaimana ia dapat menggerakkan kemampuannya yang terbaik untuk kepentingan kelompok atau organisasinya. Seringkali kita menjumpai adanya pemimpin yang menggunakan kekuasaannya secara mutlak dengan memerintahkan para bawahannya tanpa memperhatikan keadaan yang ada pada bawahannya. Hal ini jelas akan menimbulkan suatu hubungan yang tidak harmonis dalam organisasi.

Dalam melaksanakan proses kepemimpinan tersebut biasanya orang yang melakukan hal tersebut haruslah juga mempunyai jiwa pemimpin sebagai pribadi manusia. Pemimpin adalah seorang pribadi yang memiliki kecakapan dan kelebihan khususnya kecakapan dan kelebihan di satu bidang, sehingga dia mampu mempengaruhi orang lain untuk bersama-sama melakukan aktivitas-aktivitas tertentu demi pencapaian satu atau beberapa tujuan (Kartono, 2001).

Setiap tindakan manusia mempunyai suatu tujuan atau motivasi baik itu disadari maupun tidak disadari yang dimaksudkan untuk memenuhi kebutuhan yang bersangkutan. Demikian pula setiap pekerjaan atau kegiatan pegawai mempunyai suatu motivasi misalnya dia mengaharapkan penghasilan atau gaji, kepuasan pribadi dari hasil karyanya, peningkatan status, penghargaan dari pegawaipegawai sejawat, dari atasannya dan lain-lain. Pegawai sebagai makhluk sosial dalam bekerja tidak hanya mengejar penghasilan saja tetapi juga mengharapkan bahwa dalam bekerja ia dapat diterima dan dihargai oleh sesama pegawai, dia pun juga akan lebih berbahagia apabila dapat menerima dan membantu pegawai lain. Motivasi kerja adalah kemauan kerja pegawai yang timbulnya karena adanya dorongan dari dalam pribadi pegawai yang bersangkutan sebagai hasil integrasi dari keseluruhan dari pada kebutuhan pribadi, pengaruh lingkungan fisik dan pengaruh lingkungan sosial dimana kekuatannya tergantung dari pada proses pengintegrasian tersebut (Pandji Anoraga, 2003).

Motivasi memiliki akar kata motif. Motif adalah pendorong manusia untuk bertindak dan berbuat. Motif merupakan sebagai suatu pernyataan batin yang berwujud daya kekuatan 
untuk bertindak atau bergerak secara langsung atau melalui saluran perilaku yang mengarah terhadap sasaran. (Handayaningrat, 1995). Seseorang yang sangat termotivasi, yaitu orang yang melaksanakan upaya substansial guna menunjang tujuan-tujuan kesatuan kerjanya dan organisasi di mana dia bekerja. Seseorang yang tidak termotivasi hanya akan memberikan upaya minimum dalam setiap pekerjaan yang dilakukannya (Winardi, 2000).

Dengan demikian dapat disimpulkan bahwa ada suatu faktor pendorong mengapa manusia itu berbuat dan bertindak. Faktor pendorong atau motif ini seringkali diidentifikasi dengan kebutuhan dan keinginan, baik berupa kebutuhan yang sifatnya fisik maupun non fisik, motivasi diartikan sebagai suatu dorongan dalam diri manusia untuk melakukan suatu perbuatan. Motivasi adalah perasaan atau keinginan seseorang yang berada dan bekerja pada kondisi tertentu untuk melaksanakan tindakan-tindakan yang menguntungkan dilihat dari perspektif pribadi dan terutama organisasi (Danim, 2004). Motivasi merupakan daya dorong bagi seseorang untuk memberikan kontribusi yang sebesar mungkin demi keberhasilan organisasi agar tujuannya tercapai (Sondang P. Siagian, 2002).

Faktor lain yang mempengaruhi disiplin kerja pegawai adalah motivasi kerja. Motivasi mempunyai sifat yang tidak lepas dari sifat manusia yang secara individual mempunyai kualitas yang berbeda satu sama lain. Motivasi menjadi aktualisasi seorang pegawai untuk meningkatkan kinerjanya. Di dalam organisasi maupun perusahaan, interaksi yang terjadi adalah antar manusia yang berperilaku berbeda. Oleh karena itu, motivasi ini mempunyai subjek yang amat penting bagi seorang pemimpin atau manajer, karena seorang pemimpin atau manajer harus bekerja sama dengan orang lain.

Objek dari penelitian ini adalah pegawai yang bekerja di PT. Bank Muamalat Indonesia cabang Pematangsiantar. Berbicara tentang perbankan, PT. Bank Muamalat Indonesia merupakan bagian dari perbankan nasional. Keyakinan pada kebenaran perekonomian dan kegiatan muamalat yang sesuai dengan syariah, dan penerimaan masyarakat atas kegiatan perbankan syariah, telah memberikan semangat kepada PT. Bank Muamalat Indonesia untuk memberikan pelayanan terbaik dengan berlandaskan empat prinsip operasional, yakni: keadilan, kemitraan, keterbukaan, dan universalitas; yang berorientasi pada pelayanan seluruh golongan masyarakat tanpa membedakan latar belakang suku, agama, dan ras.

Dalam melaksanakan setiap kegiatan pekerjaan, ibadah merupakan orientasi utama yang menjadi prinsip dalam melaksanakan setiap aktivitas pekerjaan. Inilah yang menjadi motivasi utama seluruh unsur organisasi PT. Bank Muamalat Indonesia khususnya pegawai serta yang paling utama adalah pemimpin untuk bekerja sebaik-baiknya. Karena pekerjaan bukan hanya menjadi tanggung jawab pribadi, tetapi juga tanggung jawab kepada Tuhan. Karena itu setiap disiplin akan dilaksanakan dengan sebaik-baiknya karena bukan hanya pemimpin yang mengawasi, melainkan juga Tuhan. Dan karena itulah disiplin menjadi satu hal yang dilaksanakan dengan penuh kerelaan.

\section{METODE PENELITIAN}

Penelitian ini mengambil studi pengaruh kepemimpinan dan motivasi kerja terhadap disiplin kerja pegawai PT. Bank Muamalat Indonesia cabang Pematangsiantar, Sumatera Utara. Menurut Suharsimi Arikunto, apabila populasi kurang dari 100 orang maka sampel dapat diambil secara keseluruhan, sedangkan populasi di atas 100 orang maka sampel diambil $10 \%-15 \%$ atau $20 \%-25 \%$ dari populasi. Dan karena populasi dalam penelitian ini berjumlah 25 orang, maka sampel yang diambil dalam penelitian ini adalah: $n=25$ (Suharsimi Arikunto, 2006). Pengumpulan data penelitian ini dilakukan dengan menggunakan data primer yaitu pengumpulan data yang dilakukan 
secara langsung pada lokasi penelitian dan data sekunder yaitu pengumpulan data yang dilakukan dengan mengumpulkan data-data yang berkaitan dengan penelitian ini baik melalui buku, jurnal, majalah, artikel, internet atau pun yang lainnya. Dalam pengolahan data dalam penelitian ini menggunakan hubungan antara variabel independen (bebas) yaitu kepemimpinan $\left(X_{1}\right)$ dan motivasi kerja $\left(X_{2}\right)$ serta variabel dependen (terikat) disiplin kerja pegawai (Y). Adapun uji hipotesis yang dipakai menggunakan regresi linier sederhana dan regresi linier berganda.

\section{HASIL DAN PEMBAHASAN}

\section{Hasil Pengolahan Data}

\section{a. Uji Validitas}

Uji validitas yang dilakukan menggunakan SPSS (Statistical Product and Service Solution) versi 22.0, dengan kriteria sebagai berikut:

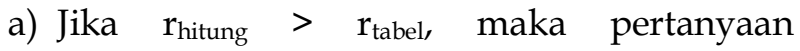
dinyatakan valid.J

b) ika $r_{\text {hitung }}<r_{\text {tabel, }}$ maka pertanyaan dinyatakan tidak valid.

Pada tahap survei, kuesioner yang berisikan 15 pertanyaan yang menyangkut antara variabel independen (bebas) yaitu kepemimpinan $\left(\mathrm{X}_{1}\right)$ dan motivasi kerja $\left(\mathrm{X}_{2}\right)$ serta variabel dependen (terikat) disiplin kerja pegawai (Y) pada PT Bank Muamalat Indonesia cabang Pematangsiantar dapat dijelaskan dalam bentuk tabel berikut ini:

Tabel 1. Validitas Tiap Pertanyaan

\begin{tabular}{cccc}
\hline PERTANYAAN & $\begin{array}{c}\mathbf{r}_{\text {hitung }} \\
\text { (Corrected } \\
\text { Item - Total } \\
\text { Correlation) }\end{array}$ & $\mathbf{r}_{\text {tabel }}$ & VALIDITAS \\
\hline Butir 1 & 0.4678 & 0.2550 & Valid \\
\hline Butir 2 & 0.6952 & 0.2550 & Valid \\
\hline Butir 3 & 0.5991 & 0.2550 & Valid \\
\hline Butir 4 & 0.6784 & 0.2550 & Valid \\
\hline Butir 5 & 0.7336 & 0.2550 & Valid
\end{tabular}

\begin{tabular}{cccc}
\hline PERTANYAAN & $\begin{array}{c}\mathbf{r}_{\text {hitung }} \\
\text { (Corrected } \\
\text { Item - Total } \\
\text { Correlation) }\end{array}$ & $\mathbf{r}_{\text {tabel }}$ & VALIDITAS \\
\hline Butir 6 & 0.5991 & 0.2550 & Valid \\
\hline Butir 7 & 0.4997 & 0.2550 & Valid \\
\hline Butir 8 & 0.3123 & 0.2550 & Valid \\
\hline Butir 9 & 0.7302 & 0.2550 & Valid \\
\hline Butir 10 & 0.6281 & 0.2550 & Valid \\
\hline Butir 11 & 0.4074 & 0.2550 & Valid \\
\hline Butir 12 & 0.4853 & 0.2550 & Valid \\
\hline Butir 13 & 0.5853 & 0.2550 & Valid \\
\hline Butir 14 & 0.7047 & 0.2550 & Valid \\
\hline Butir 15 & 0.3401 & 0.2550 & Valid \\
\hline
\end{tabular}

Dari tabel di atas dapat dilihat bahwa korelasi antara Corrected Item - Total Correlation bahwa antara skor item dengan skor item total yang digunakan untuk menguji validitas instrumen. Pada signifikansi dengan derajat bebas 0.2550. Dari tabel tersebut dapat dilihat bahwa semua pertanyaan sudah valid.

\section{b. Uji Reliabilitas}

Butir pertanyaan yang sudah dinyatakan valid dalam uji validitas ditentukan reliabilitasnya dengan kriteria sebagai berikut:

a. Jika $\mathrm{r}_{\text {alpha }}$ positif atau lebih besar dari $\mathrm{r}_{\text {tabel }}$ maka pertanyaan dinyatakan reliabel.

b. Jika $\mathrm{r}_{\text {alpha }}$ negatif atau lebih kecil dari $\mathrm{r}_{\text {tabel }}$ maka pertanyaan dinyatakan tidak reliabel.

Tabel 2. Reliabilitas Kuesioner

\begin{tabular}{cc}
\hline $\mathbf{r}_{\text {alpha }}$ & Jumlah Pertanyaan \\
\hline $\mathbf{0 . 6 3 1 1}$ & 15
\end{tabular}

Pada 15 butir pertanyaan pada tingkat signifikansi 5\%, koefisien alpha sebesar 0.6311 . Ini berarti $\mathrm{r}_{\text {alpha }}=0.6311>\mathrm{r}_{\text {tabel }}$ yaitu 0.2550 , sehingga dapat dinyatakan bahwa kuesioner 
tersebut telah reliabel dan dapat disebarkan kepada responden untuk dapat dijadikan sebagai instrumen penelitian ini.

\section{Analisis Regresi Linier Berganda}

Analisis regresi linier berganda pada penelitian ini dapat dilihat pada tabel di bawah ini:

Tabel 3. Analisis Regresi Linier Berganda

\begin{tabular}{|c|c|c|c|c|c|}
\hline \multirow[t]{2}{*}{ Model } & \multicolumn{2}{|c|}{$\begin{array}{l}\text { Unstandardized } \\
\text { Coefficients }\end{array}$} & \multirow{2}{*}{$\begin{array}{c}\begin{array}{c}\text { Standardized } \\
\text { Coefficients }\end{array} \\
\text { Beta }\end{array}$} & \multirow[t]{2}{*}{$t$} & \multirow[t]{2}{*}{ Sig. } \\
\hline & B & Std. Error & & & \\
\hline 1.(Constant) & 30.083 & 7.766 & & 4.001 & .000 \\
\hline $\mathrm{X} 1$ & 0.090 & 0.141 & 0.102 & 0.676 & 0.465 \\
\hline $\mathrm{X} 2$ & 0.255 & 0.156 & 0.178 & 0.875 & 0.232 \\
\hline
\end{tabular}

Berdasarkan hasil pengolahan data seperti terlihat pada tabel 3 kolom 2 bagian $\mathrm{B}$ diperoleh persamaan regresi linier berganda $Y=30.083+$ $0.90 \mathrm{X}_{1}+0.255 \mathrm{X}_{2}$. Dari persamaan tersebut dapat digambarkan sebagai berikut:

a. Konstanta $(\mathrm{a})=30.083$, menunjukkan harga konstan, dimana jika nilai variabel $\mathrm{X}_{1}$, dan $\mathrm{X}_{2}$ $=0$, maka disiplin kerja pegawai $(Y)=30.083$.

b. Koefisien $X_{1}\left(b_{1}\right)=0.090$, menunjukkan bahwa variabel Kepemimpinan $\left(X_{1}\right)$ berpengaruh positif terhadap disiplin kerja pegawai (Y). Dengan kata lain jika variabel kepemimpinan ditingkatkan sebesar satu satuan maka motivasi kerja karyawan akan bertambah sebesar 0.090 .

c. Koefisien $\mathrm{X}_{2}\left(\mathrm{~b}_{2}\right)=0.255$, menunjukkan bahwa variabel motivasi kerja pegawai $\left(X_{2}\right)$ berpengaruh positif terhadap disiplin kerja pegawai (Y). Dengan kata lain jika variabel motivasi kerja pegawai ditingkatkan sebesar satu satuan maka motivasi kerja karyawan akan bertambah sebesar 0.255 .

\section{Pengujian Hipotesis}

a. Uji $t_{\text {hitung }}$ (Parsial)

Uji $\mathrm{t}$ dilakukan untuk menguji secara parsial apakah variabel kepemimpinan $\left(X_{1}\right)$ dan motivasi kerja pegawai $\left(\mathrm{X}_{2}\right)$ dari PT. Bank Muamalat Indonesia cabang Pematangsiantar secara parsial atau masing-masing berpengaruh signifikan terhadap motivasi kerja pegawai. Model hipotesis yang digunakan adalah: a) $\mathrm{H}_{0}: \mathrm{b}_{1}, \mathrm{~b}_{2}=0$, variabel bebas secara parsial tidak berpengaruh signifikan terhadap variabel terikat.

b) $H_{a}: b_{1}, b_{2} \neq 0$, variabel bebas secara parsial berpengaruh signifikan terhadap variabel terikat.

Nilai $t_{\text {hitung }}$ akan dibandingkan dengan nilai $t_{\text {tabel }}$ dengan tingkat kesalahan $a=5 \%$ dan derajat kebebasan $(\mathrm{df})=(25-3)$. Dengan kriteria pengujian sebagai berikut:

a) $\mathrm{H}_{0}$ diterima jika $t_{\text {hitung }}<t_{\text {tabel }}$

b) $\mathrm{H}_{0}$ ditolak jika $t_{\text {hitung }}>t_{\text {tabel }}$

Nilai $t_{\text {hitung }}$ diperoleh dengan bantuan program SPSS versi 22.0 seperti yang terlihat pada tabel di atas. Berdasarkan tabel 3 kolom ke lima, nilai thitung untuk variabel kepemimpinan $\left(\mathrm{X}_{1}\right)$ adalah 0.676 dan untuk variabel motivasi kerja $\left(X_{2}\right)$ adalah 0.875. Nilai thitung untuk variabel $X_{1}$ dan $X_{2}$ berpengaruh positif dan signifikan pada tingkat kesalahan $\alpha=5 \%$. Hal ini dapat dilihat pada kolom ke enam di mana $\mathrm{X}_{1}=0.465$ dan $\mathrm{X}_{2}=0.232<\mathrm{a}=5 \%, \mathrm{df}=(22)=$ 0.484 .

Berdasarkan kriteria uji hipotesis yaitu jika $t_{\text {hitung }}<t_{\text {tabel }}$ maka $\mathrm{H}_{0}$ diterima. Dan disimpulkan bahwa kepemimpinan dan motivasi kerja berpengaruh positif terhadap disiplin kerja pegawai pada PT. Bank Muamalat Indonesia cabang Pematangsiantar. 


\section{b. Uji $F_{\text {hitung }}$ (Uji Secara Serentak)}

Nilai Fhitung diperoleh dengan menggunakan bantuan program SPSS versi 22.0 seperti yang terlihat pada tabel berikut ini:

Tabel 4. Hasil Uji Fhitung

ANOVA $^{b}$

\begin{tabular}{lcccccc}
\hline \multirow{2}{*}{ Model } & $\begin{array}{c}\text { Sum of } \\
\text { Squares }\end{array}$ & Df & Square & F & Sig. \\
\hline 1. & Regression & 5.105 & 2 & 2.552 & 3.287 & $.411^{\text {a }}$ \\
& & & & & & \\
\cline { 2 - 6 } & Residual & 101.077 & 30 & 3.369 & & \\
& & & & & \\
\hline Total & 106.182 & 32 & & &
\end{tabular}

a. Predictors: (Constant), $\mathrm{X}_{2}, \mathrm{X}_{1}$

b. Dependent Variable: $Y$

Pada tabel 4 kolom kelima nilai $\mathrm{F}_{\text {hitung }}=$ 3.287. Pada tingkat kesalahan $a=5 \%$, nilai $F_{\text {hitung }}$ tersebut signifikan. Pada kolom ke enam nilai signifikan $=0.411<$ tingkat kesalahan $\alpha=$ $5 \%$. Pada derajat kebebasan $(\mathrm{df})=(25-3),(3-$ $1)$, nilai $F_{\text {tabel }}=3.101$. Berdasarkan kriteria uji hipotesis jika $F_{\text {hitung }}>\mathrm{F}_{\text {tabel }}$ maka $\mathrm{H}_{1}$ diterima. Artinya variabel $X_{1}$ dan variabel $X_{2}$ secara bersama-sama berpengaruh positif dan signifikan terhadap variabel $Y$.

\section{c. Pengujian Koefisien Determinan $\left(\mathbf{R}^{2}\right)$}

Hasil pengujian koefisien determinasi dalam penelitian dapat terlihat pada tabel di bawah ini:

\section{Tabel 5. Pengujian Koefisien Determinasi}

\begin{tabular}{ccccc}
\hline Model & $\mathrm{R}$ & $\begin{array}{c}\mathrm{R} \\
\text { Square }\end{array}$ & $\begin{array}{c}\text { Adjusted } \\
\mathrm{R} \text { Square }\end{array}$ & $\begin{array}{c}\text { Std. Error } \\
\text { of the } \\
\text { Estimate }\end{array}$ \\
\hline 1 & $.550^{\mathrm{a}}$ & .448 & .379 & 2.220 \\
\hline
\end{tabular}
a. Predictors: (Constant), $\mathrm{X}_{2}, \mathrm{X}_{1}$
b. Dependent Variable: $Y$

Berdasarkan tabel 5 di atas dapat diketahui bahwa koefisien korelasi sebesar 0.550 yang menunjukkan adanya hubungan yang sangat kuat dimana koefisien determinasi $\left(R^{2}\right)$ yang telah disesuaikan sebesar 0.379 berada di antara $0 \leq \mathrm{R}^{2} \leq 1$. Hal ini menunjukkan variasi naik turunnya disiplin kerja karyawan PT. Bank Muamalat Indonesia cabang Pematangsiantar dipengaruhi oleh variabel kepemimpinan dan motivasi kerja sebesar $37,9 \%$.

\section{SIMPULAN}

Penelitian ini bertujuan untuk untuk mengetahui pengaruh kepemimpinan dan motivasi kerja terhadap disiplin pegawai di PT. Bank Muamalat Indonesia cabang Pematangsiantar. Pengumpulan data penelitian ini dilakukan dengan menggunakan data primer yaitu pengumpulan data yang dilakukan secara langsung pada lokasi penelitian dan data sekunder yaitu pengumpulan data yang dilakukan dengan mengumpulkan data-data yang berkaitan dengan penelitian ini baik melalui buku, jurnal, majalah, artikel, internet atau pun yang lainnya.

Dalam pengolahan data dalam penelitian ini menggunakan hubungan antara variabel independen (bebas) yaitu kepemimpinan $\left(X_{1}\right)$ dan motivasi kerja $\left(X_{2}\right)$ serta variabel dependen (terikat) disiplin kerja pegawai (Y). Variabel kepemimpinan $\left(X_{1}\right)$ dan motivasi kerja $\left(X_{2}\right)$ secara bersama-sama berpengaruh positif dan signifikan terhadap motivasi kerja pada PT. Bank Muamalat Indonesia cabang Pematangsiantar. Hal ini dapat dilihat dari nilai $\mathrm{F}_{\text {hitung }}=3.287>$ nilai $\mathrm{F}_{\text {tabel }}=3.101$. Pada tingkat kesalahan $\mathrm{a}=5 \%$, nilai $\mathrm{F}_{\text {hitung }}$ tersebut dinyatakan signifikan, dengan signifikansi $=$ 0.411 < tingkat kesalahan $a=5 \%$. Nilai $t_{\text {hitung }}$ untuk variabel kepemimpinan $\left(X_{1}\right)$ adalah 0.676 , untuk variabel motivasi kerja pegawai $\left(X_{2}\right)$ adalah 0.875. Berdasarkan kriteria uji hipotesis yaitu jika $t_{\text {hitung }}<t_{\text {tabel }}$ maka $\mathrm{H}_{0}$ diterima. Melalui identifikasi determinasi diketahui bahwa koefisien korelasi sebesar 0.550 yang menunjukkan adanya hubungan yang sangat kuat di mana koefisien determinasi $\left(\mathrm{R}^{2}\right)$ sebesar 0.326 berada di antara $0 \leq R^{2} \leq 1$. Dan dapat disimpulkan bahwa variabel kepemimpinan 
dan motivasi kerja pegawai berpengaruh signifikan terhadap disiplin kerja pegawai pada kantor PT. Bank Muamalat Indonesia cabang Pematangsiantar.

\section{DAFTAR PUSTAKA}

Anoraga, P. (2003). Psikologi Kepemimpinan. Jakarta: Rineka Cipta.

Arikunto, S. (2002). Metodologi Penelitian. Jakarta: Rineka Cipta.

Brahmasari. (2008). Pengaruh Motivasi Kerja, Kepemimpinan dan Budaya Organisasi Terhadap Kepuasan Kerja Karyawan Serta Dampaknya Pada Kinerja Perusahaan (Studi Kasus Pada PT. Pei Hai International Wiratama Indonesia). Jurnal Manajemen dan Kewirausahaan Universitas 17 Agustus Surabaya. Vol 10 (2), 124-135.

Danim. (2004). Motivasi Kepemimpinan dan Efektivitas Kelompok. Jakarta: Penerbit Rineka Cipta.

Handayaningrat. (1995). Azas-Azas Organisasi Manajemen. Jakarta: CV. Mas Agung.

Hasibuan, M. S. P. (2006). Manajemen Sumber Daya Manusia. Jakarta: PT. Haji Masagung.

Kartono. (2001). Pemimpin dan Kepemimpinan. Jakarta: PT. Raja Grafindo Persada.

Siagian, S. P. (2002). Kiat Meningkatkan Produktivitas Kerja. Jakarta: Rineka Cipta.

Winardi. (2000). Kepemimpinan dalam Manajemen. Jakarta: Rineka Cipta. 